\title{
Dietary and economic effects of eliminating shortfall in fruit intake on nutrient intakes and diet cost
}

\author{
Colin D. Rehm ${ }^{1 *}$ and Adam Drewnowski ${ }^{1,2}$
}

\begin{abstract}
Background: Children in the United States do not consume the recommended amounts of fruit. The economic and dietary consequences of meeting the shortfall in fruit consumption have not been evaluated.

Methods: Analyses were based on a nationally representative sample of 4-18 year-old children $(n=2,647)$ from the 2009-2010 National Health and Nutrition Examination Survey (NHANES). The shortfall in total fruit consumption for each child was estimated based on the USDA MyPlate recommendations. The potential impact of filling the shortfall in total fruit consumption was projected with whole fruit alone (WF model) or a combination of $100 \%$ fruit juice and whole fruit (FJ + WF model). Juice consumption was capped using American Academy of Pediatrics (AAP) standards. The USDA national food prices database was used to estimate the cost of meeting the dietary recommendations for fruit. Selected nutrient and mineral intakes, as well as daily diet cost were estimated after eliminating the shortfall in fruit consumption.
\end{abstract}

Results: Among all children, vitamin C (+22.8 mg [95 \% Cl 21.4, 24.1] in the WF model and $+48.1 \mathrm{mg}[95 \% \mathrm{Cl} 45.2$, $51.1]$ in the FJ + WF model) and potassium intakes (+203 mg [95\% Cl 190, 215] in WF and $+263 \mathrm{mg}[95 \% \mathrm{Cl} 248$, 280] in FJ + WF) were increased in both models. The FJ + WF model resulted in a marginal increase in dietary fiber (e.g., a relative change less than $10 \%$ ), while the WF model resulted in a meaningful increase in dietary fiber (e.g., a relative change greater than $10 \% ;+2.2 \mathrm{~g}[95 \% \mathrm{Cl} 2.1,2.3])$. Conversely, the WF model resulted in only a marginal increase in calcium, while the FJ + WF model resulted in a meaningful increase in calcium (+85 mg $[95 \% \mathrm{Cl} 79,89])$. Calories were increased in all models (+4.5\% [95 \% Cl 4.1, 4.9\%] for FJ + WF and +3.5\% [95 \% Cl 3.2, 3.7 \%] for WF). Meeting the fruit shortfall with whole fruit alone increased estimated diet costs by $9.9 \%(+\$ 0.44 / \mathrm{d}[95 \% \mathrm{Cl} 0.42,0.47])$, while the fruit juice/whole fruit combination increased diet costs by $5.2 \%$ (+\$0.23/d [95 \% Cl 0.22, 0.25]).

Conclusions: Meeting fruit consumption guidelines without a substantial increase in diet costs may be a challenge. Combining whole fruit with $100 \%$ fruit juice capped at AAP standards may be one approach to meeting fruit recommendations within cost constraints. Identifying approaches to increasing whole fruit consumption in as cost-neutral a fashion as possible should be a priority.

Keywords: Diet, Nutritional status, Fruit, Child nutrition sciences, Nutrition policy

\footnotetext{
* Correspondence: crehm@uw.edu

${ }^{1}$ Department of Epidemiology and Center for Public Health Nutrition,

University of Washington, Box 353410, Seattle, WA 98195, USA

Full list of author information is available at the end of the article
} 


\section{Background}

Dietary intakes of fruit by US children fall far short of national recommendations $[1,2]$. The Choose MyPlate recommends consuming between 1.0 to 2.5 cups of fruit per day, depending on age, gender, and physical activity [3]. By contrast, the estimated mean daily intakes for fruit (including $100 \%$ fruit juice) for $4-18 y$ olds are about 1 cup per day, though older children consume less [4]. For reference, 1.0 cup of fruit corresponds to a small apple (106 g), large banana (136 g), 32 seedless grapes $(160 \mathrm{~g})$, large orange (184 g), 8 large strawberries (166 g) or 1 cup of fruit juice (248 g or 8 fluid ounces). Numerous interventions, in pre-school [5], school [6], and family settings [7] have been developed to address the shortfall and fruit consumption and to improve the quality of children's diets, though fruit consumption remains well below recommended levels. Consuming adequate amounts of fruit is important in ensuring nutrient adequacy, particularly for vitamin $C$, potassium, and dietary fiber, and may also reduce the risk of weight gain due to their low energy density $[1,2]$. Furthermore, fruit consumption in childhood predicts fruit consumption in adulthood, which may reduce the risk of some chronic diseases, including cardiovascular disease $[8,9]$.

Approximately, $40 \%$ of total fruit consumed by children comes from $100 \%$ fruit juice [4]. The consumption of $100 \%$ fruit juice, in observational studies, has been found to be associated with an increased risk of childhood obesity, and some prospective studies among adults have observed that juice consumption is associated with an increased risk of diabetes [10-12]. One argument is that sugar consumption in the absence of dietary fiber is associated with excess weight gain, liver injury and the metabolic syndrome [10]. To this end, the American Academy of Pediatrics (AAP) recommends $100 \%$ fruit juice be limited to $4-6 \mathrm{fl} \mathrm{oz}$ for children aged 1-6y and 8-12 fl oz for children 7-18y [13]. The American Heart Association recommends no more than 4-6 fl oz of fruit juice per day and the new food package for the Women, Infants and Children (WIC) program reduced $100 \%$ juice allowances by half [14].

The consumption of total fruit by children in the United States follows a socioeconomic gradient $[4,6,15,16]$. In a study based on 1999-2002 NHANES data, fruit consumption among children was associated with living in a food secure and higher income household [4]. In modeled systems, replacing energy dense foods with vegetables and fruit led to a sharp increase in diet costs [17]. Observational studies also show that the diets of individuals consuming higher cost diets typically contain more total fruit than diets of individuals consuming lower cost diets, with the disparity being particularly apparent for whole fruits $[18,19]$. On a per-calorie basis among adults, more costly diets contained significantly more whole fruit than lower cost diets $[18,19]$. The high cost of whole fruits on a percalorie basis is one possible factor explaining the socioeconomic gradient in whole fruit consumption [20, 21].

Therefore, increasing children's fruit intake represents an economic and a behavioral challenge. While behavioral/ educational interventions have been discussed in detail [22-25], there are limited studies on the nutritional and economic impact of replacing juice with fruit or vice versa [26]. The present study explored the economic and nutritional impact of reaching the dietary recommendations for fruit using either whole fruit or a combination of fruit and $100 \%$ juice, using amounts in line with AAP recommendations. The nutritional outcomes of interest were total energy intake, vitamin $C$, potassium, calcium and dietary fiber.

\section{Methods}

\section{NHANES participants \& dietary assessment}

Data analyses were based on the National Health and Nutrition Examination Survey from 2009-2010. Data for 2,647 children 4-18y were available for analysis.

The NHANES 24-h dietary recall utilized a multi-pass method, where respondents reported the types and amounts of all food and beverages consumed in the preceding 24-h. For children 4-5y, the dietary recall was completed entirely by a parent/guardian. For children $6-11 y$, the child was the primary respondent, but a proxy respondent was present and able to assist. For 12-18y olds, the child was the primary respondent, but could be assisted by an adult.

The NHANES database includes two dietary recalls for most participants. The first was completed in-person at the Mobile Examination Center with an interviewer. The second was completed over the telephone and tends to result in lower estimated energy intakes than in-person [27]. Because the goal of this project was to assess the nutritional and economic consequences of meeting fruit recommendations under different approaches, the first 24-h recall was used for all analyses and is adequate to evaluate average population-level dietary intakes [28].

To address the shortfall in fruit consumption, current consumption of total fruit, whole fruit, and $100 \%$ fruit juice, expressed in terms of cup equivalents, were estimated based on USDA data. A cup equivalent of fruit corresponds to 1 whole fruit, a cup of sliced fruit, $1 / 2$ cup of dried fruit or 1 cup of $100 \%$ juice $(8 \mathrm{fl} \mathrm{oz})$ [29]. For example, 1.0 cup of fruit corresponds to a small apple (106 g), large banana (136 g), 32 seedless grapes (160 g), large orange $(184 \mathrm{~g}), 8$ large strawberries (166 g) or 1 cup of fruit juice ( $248 \mathrm{~g}$ or 8 fluid ounces). Cup equivalents for fruit were obtained from the USDA MyPyramid Equivalents Database (MPED). Because updated MPED data were not available for the 2009-2010 NHANES data, we used the MPED addendum database from the Center for Policy and Promotion (CNPP). Analyses were 
conducted prior to the September 2013 release of the Food Patterns Equivalent Database, containing updated groups related to 2010 Dietary Guidelines. Whole fruit and fruit juices were differentiated using the 2003-2004 Center for Nutrition Policy and Promotion (CNPP) Healthy Eating Index support files, which includes information on the relative content of whole vs. fruit juice per $100 \mathrm{~g}$ for each food/beverage.

\section{The national food prices database}

The USDA CNPP national food prices database includes average national prices for more than 6000 foods and beverages that were consumed by NHANES respondents in 2003-2004. To evaluate the economic dimensions of fruit and fruit juice consumption in the more recent NHANES data, the CNPP food prices database was adjusted for inflation. To adjust food prices, first, all foods from 2009-2010 NHANES missing a 2003-2004 price were identified and a 2003-2004 price was estimated using similar foods. The 2003-2004 prices were then adjusted for inflation and price increases using food-group specific adjustment factors as food prices have not changed uniformly over time [30,31]. Food group definitions were obtained form a prior USDA study assessing food sources of sodium based on NHANES data [32], which was linked to the USDA Quarterly Food At-Home Price Database (QFAHPD) [33]. The QFAHPD includes average prices by quarter from 2004-2010 for specific food groups across multiple markets [33]. The QFAHPD included 54 food groups and the USDA food groups included 104 food groups. For example: from the USDA food categories "milk, lowfat and nonfat" was linked with "low fat milk" from the QFAHPD.

For food groups with multiple matches within the QFAHPD, price values were distributed between multiple components of a given food group, based on weighted frequency of consumption of items within each food group. For example, for "apples", we used the prices for "fresh/frozen fruit" and "canned fruit", but weighted them 0.915 and 0.085 respectively, based on the relative frequency of consumption of raw apples and applesauce. This approach weighted the quarterly prices equally, not accounting for the seasonal availability of some items. Because the QFAHPD is based on a weighted sample we accounted for the survey weights so the food group specific adjustment factors represent the change in price at the national level. The prices database represents the average retail price at the national level and assumes all food items were purchased from stores, not restaurants.

\section{Models to address fruit shortfall}

The shortfall in total fruit intake for each participant was quantified by identifying optimum amounts of total fruit by age and gender group based on the Choose
MyPlate recommendations [3]. For children 4-5y and girls $6-8 y, 1.0$ cup was the reference value. For boys $6-8 y$, all children $9-12 y$, and girls $13-18 y, 1.5$ cups was the reference value. For boys $13-18$, 2 servings was the reference value. The shortfall was defined as the difference between the reference value and the amount consumed by each participant assuming that the participant consumed less than the reference amount.

Models were then developed to obtain the recommended amount of total fruit. In the Fruit Juice plus Whole Fruit (FJ + WF) Model, dietary recommendations for fruit were reached using a combination of $100 \%$ fruit juice and whole fruit, though the amount of $100 \%$ fruit juice that could be used to achieve the recommended fruit intake was capped at the level recommended by the American Academy of Pediatrics (1.5 servings of fruit juice for age $8+$ and 0.63 for age 4-7) and whole fruit was used thereafter [13]. The limit applied both to fruit juice consumed and juice included in the modeling. An individual consuming more than 1.5 servings of whole fruit would only have up-to 1.5 servings of $100 \%$ fruit juice used in the models. While individuals already consuming more than 1.5 servings of fruit juice (or 0.63 for young children) were included in the analysis, in no case did the modeling increase the number of fruit juice servings beyond the recommended maximum number of servings. An alternative Whole Fruit (WF) Model was specified that met dietary recommendations for total fruit using whole fruit alone, including fresh, frozen, canned and dried varieties, which were weighted by their frequency of consumption.

Rather than selecting arbitrary whole fruits and fruit juices for modeling, a composite whole fruit and fruit juice was created based on a weighted estimate using their relative frequency of consumption. For whole fruits, all fresh, canned, frozen and dried fruit that were not part of mixed dishes and consumed by children $4-18$ y were flagged. For fruit juices, all $100 \%$ fruit juices were flagged. The number of times each item was reported was used to derive a weight for the composite fruit (e.g., fresh apples were consumed 426 times and had a weight of 0.223 ). The most important whole fruits were apples (weight $=0.223$ ), bananas (0.145), oranges (0.097), grapes (0.095), and strawberries (0.067). While canned, frozen and dried fruit are lower-cost fruit sources, they were infrequently consumed (e.g., their collective weight was 0.12). The fruit juices most heavily weighted in the composite fruit juice were orange juice without calcium (weight $=0.270$ ), orange juice with calcium (0.196), apple juice (0.191), fruit juice blends (0.153), and grape juice (0.051).

\section{Analytical approach}

The outcomes of interest were important vitamins and minerals from whole fruit and $100 \%$ fruit juice, 
including vitamin $\mathrm{C}$, dietary fiber, calcium, and potassium. Fiber, calcium and potassium were all identified in the 2010 Dietary Guidelines for Americans as nutrients of concern [2]. Vitamin C was selected because fruit is an important source of this nutrient [2]. Estimated daily diet cost was an additional outcome. The surveyweighted mean value for the nutrients and diet cost measure was calculated as observed and based on the models. Data are presented for the entire population and for those children with a fruit shortfall for all children/ adolescents and stratified by age group (4-8y, 9-13y and 14-18y). Additional stratified analyses were conducted by race/ethnicity and family income. For models conducted with the shortfall population only, the diets of children consuming adequate amounts of fruit was not altered.

By the nature of the models, energy, micronutrient/ mineral, and diet costs were all statistically greater after removing the fruit shortfall (i.e., because the amount of food consumed requisitely increased). Because of this, $p$ values comparing the observed mean to the modeled mean are not estimated, rather we present data on the relative and absolute changes along with corresponding $95 \%$ confidence intervals (CI). All analyses accounted for the complex survey design of NHANES data using Stata 13 (StataCorp, College Station, TX). Because the nature of the models resulted in highly statistically significant changes in the dietary outcomes being evaluated, qualitative comparisons were considered based on the percent change from the observed diets. A $10 \%$ change was considered qualitatively meaningful, while a change of less than $10 \%$ was considered to be marginal or modest.

\section{Ethical approval and availability of supporting data}

Publicly available data, such as those from NHANES, are considered exempt from Human Subjects review per University of Washington policies. All data used in this research are available to the public at the websites for the National Center for Health Statistics and the Agriculture Research Service of the United States Department of Agriculture.

\section{Results}

Table 1 shows mean servings of total fruit, whole fruit and $100 \%$ fruit juice, as well as estimated daily diet cost by age group, gender, income to poverty ratio and race/ ethnicity. Overall, children and adolescents consumed 1.1 (95\% CI 1.0, 1.2) servings of total fruit per day, $59 \%$ from whole fruit and the remainder from fruit juice. Most children $(68.8 \%)$ had a shortfall in fruit consumption. Fruit consumption did not differ substantially by gender. Younger children consumed significantly more total fruit and whole fruit than older children.

Table 1 Mean servings of total fruit, whole fruit, and $100 \%$ fruit juice and estimated diet cost by age group, gender, family income-to-poverty ratio, and race/ethnicity among children and adolescents age 4-18y, NHANES 2009-2010 ( $n=2,647)$

\begin{tabular}{|c|c|c|c|c|c|}
\hline & $\mathrm{n}$ & $\begin{array}{l}\text { Total fruit }{ }^{a} \\
(95 \% \mathrm{Cl})\end{array}$ & $\begin{array}{l}\text { Whole fruit } \\
(95 \% \mathrm{Cl})\end{array}$ & $\begin{array}{l}\text { Fruit juice } \\
(95 \% \mathrm{Cl})\end{array}$ & $\begin{array}{l}\text { Estimated diet cost (\$) } \\
(95 \% \mathrm{Cl})\end{array}$ \\
\hline Total & 2,647 & $1.11(1.00,1.22)$ & $0.66(0.58,0.74)$ & $0.44(0.38,0.51)$ & $4.48(4.28,4.69)$ \\
\hline \multicolumn{6}{|l|}{ Gender } \\
\hline Female (ref) & 1,282 & $1.05(0.94,1.17)$ & $0.64(0.55,0.73)$ & $0.41(0.34,0.48)$ & $4.12(3.95,4.29)$ \\
\hline Male & 1,365 & $1.16(1.02,1.30)$ & $0.68(0.58,0.78)$ & $0.48(0.39,0.57)$ & $4.85(4.56,5.14)^{\#}$ \\
\hline \multicolumn{6}{|l|}{ Age group (y) } \\
\hline $4-8$ & 958 & $1.29(1.16,1.43)^{n}$ & $0.78(0.68,0.88)^{*}$ & $0.51(0.44,0.59)$ & $3.83(3.73,3.93)^{\#}$ \\
\hline $9-13$ & 887 & $1.00(0.89,1.11)$ & $0.62(0.56,0.68)$ & $0.38(0.29,0.47)$ & $4.42(4.30,4.54)^{\#}$ \\
\hline 14-18 (ref) & 802 & $1.03(0.84,1.22)$ & $0.59(0.41,0.76)$ & $0.44(0.33,0.55)$ & $5.15(4.68,5.62)$ \\
\hline \multicolumn{6}{|l|}{ Income-to-poverty ratio } \\
\hline$<1.3$ & 1,122 & $1.08(0.94,1.22)$ & $0.59(0.52,0.66)$ & $0.49(0.38,0.59)$ & $4.31(4.10,4.51)$ \\
\hline $1.3-2.99$ & 696 & $1.11(0.79,1.43)$ & $0.63(0.37,0.9)$ & $0.48(0.37,0.59)$ & $4.22(3.95,4.49)^{*}$ \\
\hline$\geq 3.00$ (ref) & 606 & $1.07(0.96,1.18)$ & $0.71(0.59,0.83)$ & $0.36(0.29,0.43)$ & $4.75(4.33,5.17)$ \\
\hline \multicolumn{6}{|l|}{ Race/ethnicity } \\
\hline Mexican-American & 746 & $1.34(1.06,1.61)^{*}$ & $0.75(0.63,0.88)$ & $0.59(0.41,0.77)^{*}$ & $4.23(4.02,4.44)^{*}$ \\
\hline Other Hispanic & 307 & $1.19(0.98,1.40)$ & $0.67(0.49,0.85)$ & $0.52(0.44,0.60)^{9}$ & $4.16(3.95,4.37)^{*}$ \\
\hline Non-Hispanic white (ref) & 883 & $1.00(0.85,1.14)$ & $0.65(0.52,0.79)$ & $0.34(0.28,0.40)$ & $4.58(4.28,4.88)$ \\
\hline Non-Hispanic black & 525 & $1.18(1.01,1.36)$ & $0.58(0.49,0.67)$ & $0.61(0.47,0.74)^{\#}$ & $4.37(4.07,4.68)$ \\
\hline
\end{tabular}

Reference group identified in parentheses. Statistical significance is indicated as follows; ${ }^{*} 0.01<p$-value $<0.05 ;{ }^{9} 0.001<p$-value $<0.01 ;{ }^{\#} p$-value $<0.001$

${ }^{a} \mathrm{~A}$ serving size of fruit corresponds to a cup equivalent. One cup equivalent of fruit corresponds to a small apple (106 g), large banana (136 g), 32 seedless grapes $(160 \mathrm{~g})$, large orange (184 g), 8 large strawberries (166 g) or 1 cup of fruit juice ( $248 \mathrm{~g}$ or 8 fluid ounces) 
Differences in total fruit intake were not observed by family income, though children from lower-income families received a greater proportion of their total fruit from fruit juice than those from higher-income families. Total fruit intake did differ by race/ethnicity. MexicanAmerican children consumed the most total fruit and non-Hispanic black children consumed the most fruit juice. Fifty-two percent of total fruit among nonHispanic black children came from fruit juice compared to $34 \%$ for non-Hispanic white children.

The results of modeling to meet the total fruit shortfall among all children $(n=2,647)$ and children with a shortfall in fruit consumption $(n=1,781)$ are shown in Table 2 and Table 3, respectively. Data are presented for all children and by age group. Among all children and those with a shortfall in fruit intake, the average shortfall was 0.75 (95\% CI $0.71,0.80)$ and 1.09 servings (95\% CI $1.06,1.12)$, respectively. First, meeting total fruit guidelines by whole fruit (WF) alone or a combination of fruit juice and whole fruit (FJ + WF) would increase total energy intakes by no more than $6 \%$ or less than $100 \mathrm{kcal} /$ $\mathrm{d}$, with the WF $+\mathrm{FJ}$ model resulting in greater increases in total energy than the WF model. In the FJ+WF model, vitamin $\mathrm{C}$, dietary fiber, calcium and potassium increased by $+61 \%(+48 \mathrm{mg} / \mathrm{d}),+4.7 \%(+0.7 \mathrm{~g} / \mathrm{d})$, $+7.9 \%(+85 \mathrm{mg} / \mathrm{d})$, and $+11.7 \%(264 \mathrm{mg} / \mathrm{d})$ respectively. In the WF model vitamin $C$, dietary fiber, calcium and potassium increased by $+29 \%(23 \mathrm{mg} / \mathrm{d}),+16 \%(+2.2 \mathrm{~g} /$ d), $+1.3 \%(+14 \mathrm{mg} / \mathrm{d})$, and $+9.0 \%(+203 \mathrm{mg} / \mathrm{d})$, respectively. When comparing the impacts of the two models to each other, the FJ + WF model resulted in significant increases in vitamin $\mathrm{C}(+25.1 \%$ [95 \% CI 22.2, 27.9], comparing WF $+\mathrm{FJ}$ to the FJ model), and modest increases in calcium $(6.5 \%$ [95 \% CI 5.9, 7.1) and potassium (2.5\% [95 \% CI 2.3, 2.7]), while the WF model resulted in $9.5 \%$ (95\% CI 8.7, 10.3) lower dietary fiber. The FJ + WF model resulted in a $5.2 \%$ (95 \% CI 4.7, $5.7 \%)$ increase in diet costs, while the WF model resulted in a $9.9 \%$ increase ( $95 \%$ CI 9.0, $10.8 \%$ ). Comparing the two models to each other, the WF + FJ model resulted in a $4.3 \%(95 \%$ CI 3.9, 4.6) decrease in diet cost when compared to the WF model. In general, results were similar across age groups (shown in Table 2) and when stratified by race/ethnicity and family income (data not shown).

As expected, results were stronger when restricted to the child population with a shortfall in total fruit consumption (Table 3), where energy intakes increased by $6.6 \%(95 \%$ CI $6.3,6.9)$ or $129 \mathrm{kcal}(95 \%$ CI 125, 132) and $5.1 \%(95 \%$ CI 4.8, 5.3) or $99 \mathrm{kcal}(95 \%$ CI 96, 102) in the FJ + WF and WF models, respectively. In the FJ + WF model, vitamin $C$, dietary fiber, calcium and potassium were increased by $+127 \%(+70 \mathrm{mg} / \mathrm{d}),+7.5 \%$ $(+0.9 \mathrm{~g} / \mathrm{d}),+11.8 \%(+123 \mathrm{mg} / \mathrm{d})$ and $+18.4 \%(+383 \mathrm{mg} /$ d), respectively. In the WF model, vitamin C, dietary fiber, calcium and potassium were increased by $+60 \%(+33 \mathrm{mg} /$ d), $+25 \%(+3.2 \mathrm{~g} / \mathrm{d}),+2.0 \%(+21 \mathrm{mg} / \mathrm{d})$ and $+14.1 \%$ $(+295 \mathrm{mg} / \mathrm{d})$, respectively. Similar to the results from the total population, the FJ + WF model increased vitamin C, potassium and calcium by a greater amount than the WF model, while the WF model increased dietary fiber more than the FJ + WF model. The FJ + WF model increased diet costs by $7.8 \%$ (95\% CI 7.3, $8.3 \%$ ), while the WF model increased diet costs by $14.9 \%$ (95 \% CI 13.9, 15.9). When comparing the two models to each other with regards to cost, the WF model resulted in $6.1 \%$ (95\% CI $5.8,6.5)$ or $\$ 0.31 / \mathrm{d}(95 \%$ CI $0.30,0.32)$ higher diet costs Results were generally consistent across age groups (see Table 3) and when stratified by race/ethnicity and family income (data not shown).

\section{Discussion}

The shortfall in fruit consumption by US children can be addressed in a number of ways. One is through increased consumption of whole fruit; the approach currently favored by the new WIC package, professional organizations and childcare/preschool licensors [34]. As shown, this approach would increase dietary intakes of vitamin $\mathrm{C}$, potassium, and dietary fiber by a meaningful amount (i.e., more than a $10 \%$ increase from observed diets). Since most fruits have low energy densities, this increase in dietary nutrient density can be accomplished with only a modest increase in energy intakes. However, when compared to the whole fruit plus fruit juice model, the whole fruit alone model resulted in a significantly higher diet cost, and had smaller gains for potassium, calcium and vitamin $\mathrm{C}$.

While both models increased diet costs, the addition of whole fruit alone increased diet costs by a significantly greater amount than a combination of whole fruit and fruit juice $(+\$ 0.21 / \mathrm{d}$ [95 \% CI 0.20, 0.22] for all children and $+0.31 / \mathrm{d}$ [95 \% CI 0.30, 0.32] among those with a shortfall in fruit consumption). While higher-income families may be able to more readily absorb higher diet costs, higher costs may pose a larger barrier to lowerincome families on limited food budgets. Given previous evidence of a socioeconomic gradient in fruit consumption $[4,6]$, the provision of fresh fruit may pose a challenge to this population. Further, interventions or policy changes that are not cost-neutral may pose challenges for interventions in institutional settings, including day care centers, pre-schools and schools that need to provide optimal nutrition at an affordable cost $[35,36]$.

In the FJ + WF model, the fruit shortfall was addressed through a combination of whole fruit and $100 \%$ fruit juice. The amount of juice permitted in modeling for each age group was capped by the AAP guidelines. As shown, the mixed model (whole fruit and juice) 
Table 2 Observed and model predicted total energy intake (kcal), nutrient intakes, and estimated diet cost among all children and adolescents age 4-18, NHANES 2009-2010

\begin{tabular}{|c|c|c|c|c|c|c|c|c|c|}
\hline & \multirow{2}{*}{$\begin{array}{l}\text { Observed } \\
\text { Mean (95 \% Cl) }\end{array}$} & \multicolumn{3}{|c|}{ Fruit juice + whole fruit (FJ + WF) model } & \multicolumn{3}{|c|}{ Whole fruit (WF) model } & \multicolumn{2}{|c|}{ Comparison of FJ + WF vs. WF mean } \\
\hline & & Mean $(95 \% \mathrm{Cl})$ & $\begin{array}{l}\text { Absolute change } \\
\text { from observed } \\
(95 \% \text { Cl) }\end{array}$ & $\begin{array}{l}\% \text { change from } \\
\text { observed } \\
(95 \% \mathrm{Cl})\end{array}$ & Mean $(95 \% \mathrm{Cl})$ & $\begin{array}{l}\text { Absolute change } \\
\text { from observed } \\
(95 \% \text { Cl) }\end{array}$ & $\begin{array}{l}\text { \% change from } \\
\text { observed } \\
(95 \% \mathrm{Cl})\end{array}$ & $\begin{array}{l}\text { Absolute change } \\
\text { from FJ + WF vs. } \\
\text { WF Model }(95 \% \text { Cl) }\end{array}$ & $\begin{array}{l}\% \text { change from FJ + WF } \\
\text { vs. WF model }(95 \% \text { Cl) }\end{array}$ \\
\hline \multicolumn{10}{|l|}{ Energy (kcal) } \\
\hline Overall $^{a}$ & $1969(1908,2030)$ & $2058(1999,2116)$ & $88(83,94)$ & $4.5(4.1,4.9)$ & $2037(1978,2096)$ & $68(64,72)$ & $3.5(3.2,3.7)$ & $20(19,22)$ & $1.0(0.9,1.1)$ \\
\hline Age $4-8 y^{b}$ & $1740(1688,1791)$ & $1786(1737,1836)$ & $47(40,53)$ & $2.7(2.3,3.1)$ & $1777(1727,1827)$ & $37(32,43)$ & $2.2(1.8,2.5)$ & $9(8,11)$ & $0.5(0.4,0.6)$ \\
\hline Age $9-13 y^{c}$ & $1937(1868,2006)$ & $2032(1964,2100)$ & $95(87,103)$ & $4.9(4.4,5.4)$ & $2009(1941,2077)$ & $72(66,78)$ & $3.7(3.3,4.1)$ & $23(21,25)$ & $1.2(1.0,1.3)$ \\
\hline Age $14-18 y^{d}$ & $2216(2088,2344)$ & $2338(2213,2462)$ & $122(115,129)$ & $5.5(5.0,6.0)$ & $2310(2184,2435)$ & $94(88,99)$ & $4.2(3.8,4.6)$ & $28(26,30)$ & $1.2(1.1,1.3)$ \\
\hline \multicolumn{10}{|l|}{ Vitamin C (mg) } \\
\hline Overall & $78(71,86)$ & $127(122,132)$ & $48(45,51)$ & $61.4(52.5,70.3)$ & $101(95,107)$ & $23(21,24)$ & $29.1(24.9,33.2)$ & $25(24,27)$ & $25.1(22.2,27.9)$ \\
\hline Age 4-8y & $79(71,86)$ & $103(97,108)$ & $24(21,28)$ & $30.8(23.7,37.9)$ & $91(84,98)$ & $13(11,14)$ & $15.9(12.4,19.5)$ & $12(10,13)$ & $12.8(10.1,15.5)$ \\
\hline Age 9-13y & $71(61,81)$ & $124(115,132)$ & $53(49,57)$ & $74.5(60.3,88.7)$ & $95(86,104)$ & $24(22,26)$ & $33.9(27.4,40.3)$ & $29(27,31)$ & $30.4(26.1,34.7)$ \\
\hline Age 14-18y & $85(73,98)$ & $152(141,162)$ & $66(62,70)$ & $77.8(62.5,93.1)$ & $117(105,128)$ & $31(30,33)$ & $36.7(29.6,43.9)$ & $35(33,37)$ & $30(25.7,34.4)$ \\
\hline \multicolumn{10}{|l|}{ Dietary fiber (gm) } \\
\hline Overall & $13.9(13.4,14.5)$ & $14.6(14,15.2)$ & $0.7(0.6,0.7)$ & $4.7(4.2,5.1)$ & $16.1(15.6,16.6)$ & $2.2(2.1,2.3)$ & $15.7(14.2,17.2)$ & $-1.5(-1.6,-1.4)$ & $-9.5(-10.3,-8.7)$ \\
\hline Age 4-8y & $12.9(12.4,13.4)$ & $13.4(12.9,13.9)$ & $0.5(0.4,0.6)$ & $3.8(3.2,4.5)$ & $14.1(13.7,14.6)$ & $1.2(1.0,1.4)$ & $9.3(7.8,10.8)$ & $-0.7(-0.8,-0.6)$ & $-5.0(-5.8,-4.2)$ \\
\hline Age 9-13y & $14.3(13.3,15.3)$ & $14.9(13.9,15.8)$ & $0.6(0.5,0.6)$ & $3.9(3.4,4.5)$ & $16.6(15.7,17.5)$ & $2.3(2.1,2.5)$ & $16.1(14.1,18.1)$ & $-1.7(-1.9,-1.6)$ & $-10.5(-11.7,-9.4)$ \\
\hline Age 14-18y & $14.6(13.7,15.5)$ & $15.5(14.6,16.3)$ & $0.9(0.8,0.9)$ & $6.1(5.5,6.7)$ & $17.6(16.9,18.4)$ & $3.0(2.8,3.2)$ & $20.6(18.5,22.8)$ & $-2.1(-2.3,-2.0)$ & $-12.1(-13.2,-10.9)$ \\
\hline \multicolumn{10}{|l|}{ Calcium (mg) } \\
\hline Overall & $1068(1022,1113)$ & $1152(1110,1194)$ & $85(79,90)$ & $7.9(7.2,8.7)$ & $1082(1037,1127)$ & $14(13,15)$ & $1.3(1.2,1.5)$ & $70(66,75)$ & $6.5(5.9,7.1)$ \\
\hline Age 4-8y & $1027(973,1080)$ & $1067(1014,1121)$ & $40(34,46)$ & $3.9(3.3,4.5)$ & $1035(981,1088)$ & $8(7,9)$ & $0.8(0.6,0.9)$ & $32(28,37)$ & $3.1(2.6,3.6)$ \\
\hline Age 9-13y & $1061(986,1136)$ & $1156(1081,1230)$ & $95(87,103)$ & $9.0(7.9,10.0)$ & $1076(1001,1151)$ & $15(14,16)$ & $1.4(1.3,1.6)$ & $80(73,86)$ & $7.4(6.6,8.3)$ \\
\hline Age 14-18y & $1132(1053,1211)$ & $1132(1053,1211)$ & $117(110,124)$ & $10.5(9.2,11.8)$ & $1132(1053,1211)$ & $20(19,21)$ & $1.8(1.6,2.0)$ & $97(91,103)$ & $8.6(7.5,9.6)$ \\
\hline \multicolumn{10}{|l|}{ Potassium (mg) } \\
\hline Overall & $2244(2156,2333)$ & $2508(2430,2586)$ & $264(248,280)$ & $11.7(10.7,12.8)$ & $2447(2367,2527)$ & $203(191,215)$ & $9.0(8.2,9.9)$ & $61(57,65)$ & $2.5(2.3,2.7)$ \\
\hline Age 4-8y & $2105(2021,2190)$ & $2245(2172,2318)$ & $140(120,159)$ & $6.6(5.5,7.8)$ & $2217(2142,2292)$ & $112(96,127)$ & $5.3(4.4,6.2)$ & $28(24,32)$ & $1.3(1,1.5)$ \\
\hline Age 9-13y & $2183(2067,2299)$ & $2466(2356,2575)$ & $283(259,306)$ & $13(11.5,14.4)$ & $2396(2286,2507)$ & $214(196,232)$ & $9.8(8.7,10.9)$ & $69(64,75)$ & $2.9(2.6,3.2)$ \\
\hline Age 14-18y & $2434(2266,2601)$ & $2797(2644,2950)$ & $363(342,384)$ & $14.9(13.2,16.7)$ & $2712(2556,2869)$ & $279(263,295)$ & $11.5(10.1,12.8)$ & $84(79,90)$ & $3.1(2.8,3.5)$ \\
\hline
\end{tabular}


Table 2 Observed and model predicted total energy intake (kcal), nutrient intakes, and estimated diet cost among all children and adolescents age 4-18, NHANES 2009-2010 (Continued)

\begin{tabular}{|c|c|c|c|c|c|c|c|c|c|}
\hline \multicolumn{10}{|l|}{$\operatorname{Cost}(\$ / d)$} \\
\hline \multicolumn{8}{|l|}{$\begin{array}{c}\text { Cost (\$/d) } \\
\text { Overall }\end{array}$} & & $-4.3(-4.6,-3.9)$ \\
\hline Age 4-8y & $3.83(3.73,3.93)$ & $3.98(3.89,4.07)$ & $0.15(0.13,0.17)$ & $3.8(3.2,4.4)$ & $4.08(3.99,4.17)$ & $0.24(0.21,0.28)$ & $6.4(5.4,7.3)$ & $-0.1(-0.11,-0.08)$ & $-2.4(-2.8,-2.0)$ \\
\hline Age 9-13y & $4.42(4.30,4.54)$ & $4.65(4.53,4.77)$ & $0.23(0.21,0.25)$ & $5.2(4.7,5.7)$ & $4.89(4.77,5.02)$ & $0.47(0.43,0.51)$ & $10.6(9.6,11.5)$ & $-0.24(-0.26,-0.22)$ & $-4.9(-5.3,-4.5)$ \\
\hline Age $14-18 y$ & $5.15(4.68,5.62)$ & $5.47(5.01,5.93)$ & $0.32(0.3,0.34)$ & $6.2(5.4,7.0)$ & $5.76(5.31,6.22)$ & $0.61(0.58,0.65)$ & $11.8(10.3,13.4)$ & $-0.29(-0.31,-0.27)$ & $-5.1(-5.7,-4.4)$ \\
\hline
\end{tabular}

${ }^{a}$ The mean shortfall in the overall population was $0.75(95 \% \mathrm{Cl} 0.71,0.80)$ and $68.8 \%$ had a shortfall in total fruit intake

${ }^{\mathrm{b}}$ The mean shortfall among those $4-8 y$ was $0.41(95 \% \mathrm{Cl} 0.36,0.47)$ and $53.3 \%$ had a shortfall in total fruit intake

c The mean shortfall among those $9-13 y$ was $0.79(95 \% \mathrm{Cl} 0.72,0.86)$ and $75.0 \%$ had a shortfall in total fruit intake

${ }^{d}$ The mean shortfall among those $14-18 y$ was $1.03(95 \% \mathrm{Cl} 0.97,1.09)$ and $77.9 \%$ had a shortfall in total fruit intake 
Table 3 Observed and model predicted total energy intake (kcal), nutrient intakes, and estimated diet cost among children and adolescents age 4-18 with a shortfall in total fruit consumption, NHANES 2009-2010 $(n=1,781)$

\begin{tabular}{|c|c|c|c|c|c|c|c|c|c|}
\hline & \multirow{2}{*}{$\begin{array}{l}\text { Observed } \\
\text { Mean (95 \% Cl) }\end{array}$} & \multicolumn{3}{|c|}{$\underline{\text { Fruit juice }+ \text { whole fruit (FJ }+ \text { WF) model }}$} & \multicolumn{3}{|c|}{ Whole fruit (WF) model } & \multicolumn{2}{|c|}{ Comparison of FJ + WF vs. WF mean } \\
\hline & & Mean $(95 \% \mathrm{Cl})$ & $\begin{array}{l}\text { Absolute change } \\
\text { from observed } \\
(95 \% \mathrm{Cl})\end{array}$ & $\begin{array}{l}\text { \% change from } \\
\text { observed } \\
(95 \% \text { Cl) }\end{array}$ & Mean $(95 \% \mathrm{Cl})$ & $\begin{array}{l}\text { Absolute change } \\
\text { from observed } \\
(95 \% \mathrm{Cl})\end{array}$ & $\begin{array}{l}\% \text { change from } \\
\text { observed } \\
(95 \% \text { Cl) }\end{array}$ & $\begin{array}{l}\text { Absolute change from } \\
\text { FJ + WF vs. WF Model } \\
(95 \% \text { Cl) }\end{array}$ & $\begin{array}{l}\% \text { change from FJ + WF } \\
\text { vs. WF model }(95 \% \text { Cl) }\end{array}$ \\
\hline \multicolumn{10}{|l|}{ Energy (kcal) } \\
\hline Overall $^{a}$ & $1946(1883,2009)$ & $2075(2012,2137)$ & $129(125,132)$ & $6.6(6.3,6.9)$ & $2045(1982,2108)$ & $99(96,102)$ & $5.1(4.8,5.3)$ & $30(29,30)$ & $1.4(1.4,1.5)$ \\
\hline Age $4-8 y^{b}$ & $1684(1642,1726)$ & $1772(1731,1812)$ & $88(82,94)$ & $5.2(4.8,5.6)$ & $1754(1713,1795)$ & $70(65,75)$ & $4.2(3.8,4.5)$ & $18(16,19)$ & $1.0(0.9,1.1)$ \\
\hline Age $9-13 y^{c}$ & $1906(1839,1974)$ & $2033(1970,2096)$ & $127(117,136)$ & $6.6(6.0,7.3)$ & $2002(1938,2066)$ & $96(89,103)$ & $5.0(4.5,5.5)$ & $31(29,33)$ & $1.5(1.4,1.7)$ \\
\hline Age $14-18 y^{d}$ & $2151(2030,2273)$ & $2308(2184,2433)$ & $157(151,162)$ & $7.3(6.9,7.6)$ & $2272(2148,2396)$ & $120(116,125)$ & $5.6(5.3,5.9)$ & $36(35,37)$ & $1.6(1.5,1.7)$ \\
\hline \multicolumn{10}{|l|}{ Vitamin C (mg) } \\
\hline Overall & $55(50,60)$ & $125(120,129)$ & $70(68,72)$ & $127(114,140)$ & $88(84,93)$ & $33(32,34)$ & $60.2(54.0,66.3)$ & $37(36,38)$ & $41.8(39.3,44.3)$ \\
\hline Age 4-8y & $50(41,59)$ & $96(88,104)$ & $45(42,48)$ & $90.1(70.5,110)$ & $74(65,83)$ & $24(22,25)$ & $46.7(36.6,56.7)$ & $22(20,23)$ & $29.6(24.9,34.3)$ \\
\hline Age 9-13y & $52(45,59)$ & $123(116,129)$ & $70(66,75)$ & $135(112,158)$ & $84(78,91)$ & $32(30,34)$ & $61.4(50.8,71.9)$ & $38(36,41)$ & $45.7(41.1,50.3)$ \\
\hline Age 14-18y & $61(51,70)$ & $146(135,156)$ & $85(83,88)$ & $141(119,163)$ & $101(91,111)$ & $40(39,42)$ & $66.5(56.0,76.9)$ & $45(44,47)$ & $44.7(40.5,48.8)$ \\
\hline \multicolumn{10}{|l|}{ Dietary fiber (gm) } \\
\hline Overall & $12.7(12.1,13.3)$ & $13.6(13.0,14.3)$ & $0.9(0.9,1.1)$ & $7.5(6.9,8.1)$ & $15.9(15.3,16.5)$ & $3.2(3.1,3.3)$ & $25.0(23.2,26.8)$ & $-2.2(-2.3,-2.1)$ & $-14.1(-14.9,-13.2)$ \\
\hline Age 4-8y & $11.1(10.5,11.7)$ & $12.0(11.4,12.6)$ & $0.9(0.8,1)$ & $8.4(7.3,9.5)$ & $13.3(12.8,13.9)$ & $2.3(2.1,2.4)$ & $20.4(18.5,22.3)$ & $-1.3(-1.4,-1.2)$ & $-9.9(-10.8,-9.1)$ \\
\hline Age 9-13y & $13.0(12.0,14.0)$ & $13.8(12.8,14.7)$ & $0.7(0.7,0.8)$ & $5.7(4.9,6.6)$ & $16.1(15.2,16.9)$ & $3.1(2.8,3.3)$ & $23.6(20.5,26.7)$ & $-2.3(-2.5,-2.2)$ & $-14.5(-16,-13)$ \\
\hline Age 14-18y & $13.5(12.6,14.3)$ & $14.6(13.7,15.5)$ & $1.1(1.1,1.2)$ & $8.5(7.9,9.1)$ & $17.3(16.4,18.3)$ & $3.9(3.7,4)$ & $28.7(26.9,30.6)$ & $-2.7(-2.8,-2.6)$ & $-15.7(-16.6,-14.9)$ \\
\hline \multicolumn{10}{|l|}{ Calcium (mg) } \\
\hline Overall & $1043(988,1099)$ & $1166(1112,1220)$ & $123(119,127)$ & $11.8(10.9,12.6)$ & $1064(1009,1119)$ & $21(20,21)$ & $2.0(1.9,2.1)$ & $102(99,105)$ & $9.6(8.9,10.3)$ \\
\hline Age 4-8y & $1021(956,1086)$ & $1097(1032,1162)$ & $76(71,81)$ & $7.4(6.7,8.1)$ & $1036(971,1101)$ & $15(14,16)$ & $1.4(1.3,1.6)$ & $61(57,65)$ & $5.9(5.3,6.4)$ \\
\hline Age 9-13y & $1029(957,1102)$ & $1156(1083,1229)$ & $127(118,135)$ & $12.3(11.1,13.5)$ & $1049(977,1122)$ & $20(19,22)$ & $2.0(1.8,2.1)$ & $107(99,114)$ & $10.2(9.2,11.1)$ \\
\hline Age 14-18y & $1070(987,1154)$ & $1221(1136,1305)$ & $150(145,155)$ & $14.0(13.0,15.1)$ & $1096(1012,1179)$ & $25(24,26)$ & $2.4(2.2,2.5)$ & $125(121,129)$ & $11.4(10.6,12.3)$ \\
\hline \multicolumn{10}{|l|}{ Potassium (mg) } \\
\hline Overall & $2084(2004,2163)$ & $2467(2389,2544)$ & $383(371,395)$ & $18.4(17.4,19.4)$ & $2378(2300,2457)$ & $295(285,304)$ & $14.1(13.4,14.9)$ & $88(86,91)$ & $3.7(3.5,3.9)$ \\
\hline Age 4-8y & $1897(1826,1968)$ & $2159(2099,2220)$ & $262(244,280)$ & $13.8(12.5,15.1)$ & $2107(2043,2170)$ & $209(195,224)$ & $11.0(10.0,12.1)$ & $53(49,56)$ & $2.5(2.3,2.7)$ \\
\hline Age 9-13y & $2002(1914,2091)$ & $2379(2285,2474)$ & $377(350,404)$ & $18.8(17.3,20.4)$ & $2287(2194,2380)$ & $285(263,306)$ & $14.2(13.0,15.4)$ & $92(86,99)$ & $4.0(3.8,4.3)$ \\
\hline Age 14-18y & $2278(2129,2427)$ & $2744(2592,2897)$ & $467(451,482)$ & $20.5(19.1,21.9)$ & $2636(2484,2788)$ & $358(346,371)$ & $15.7(14.7,16.8)$ & $108(105,112)$ & $4.1(3.8,4.4)$ \\
\hline
\end{tabular}


Table 3 Observed and model predicted total energy intake (kcal), nutrient intakes, and estimated diet cost among children and adolescents age 4-18 with a shortfall in total fruit consumption, NHANES 2009-2010 $(n=1,781)$ (Continued)

\begin{tabular}{|c|c|c|c|c|c|c|c|c|c|}
\hline \\
\hline $14.9(13.9,15.9)-0.31(-0.32,-0.3)$ & $4.33(4.1,4.56)$ & $4.67(4.44,4.90)$ & $0.34(0.33,0.35)$ & $7.8(7.3,8.3)$ & $4.97(4.74,5.21)$ & $0.64(0.62,0.66)$ & $14.9(13.9,15.9)$ & $-0.31(-0.32,-0.3)$ & $-6.1(-6.5,-5.8)$ \\
\hline Age 4-8y & $3.49(3.37,3.6)$ & $3.76(3.64,3.88)$ & $0.28(0.25,0.3)$ & $7.9(7.2,8.6)$ & $3.94(3.82,4.06)$ & $0.46(0.43,0.49)$ & $13.1(12.2,14.1)$ & $-0.18(-0.2,-0.17)$ & $-4.6(-5.0,-4.3)$ \\
\hline Age 9-13y & $4.24(4.12,4.35)$ & $4.54(4.42,4.66)$ & $0.3(0.28,0.33)$ & $7.2(6.5,7.9)$ & $4.86(4.74,4.97)$ & $0.62(0.58,0.67)$ & $14.7(13.4,16.0)$ & $-0.32(-0.34,-0.3)$ & $-6.6(-7.0,-6.1)$ \\
\hline Age 14-18y & $4.96(4.47,5.45)$ & $5.37(4.87,5.87)$ & $0.41(0.39,0.43)$ & $8.3(7.6,9.0)$ & $5.75(5.24,6.25)$ & $0.78(0.76,0.81)$ & $15.8(14.4,17.2)$ & $-0.37(-0.39,-0.36)$ & $-6.5(-7.1,-6.0)$ \\
\hline
\end{tabular}

${ }^{a}$ The mean shortfall in the overall population among those with a fruit shortfall was $1.09(95 \% \mathrm{Cl} 1.06,1.12)$

${ }^{\mathrm{b}}$ The mean shortfall among those $4-8 \mathrm{y}$ with a fruit shortfall was $0.78(95 \% \mathrm{Cl} 0.72,0.83)$

c The mean shortfall among those $9-13 y$ with a fruit shortfall was $1.05(95 \% \mathrm{Cl} 0.98,1.13)$

${ }^{d}$ The mean shortfall among those $14-18$ y with a fruit shortfall was 1.33 ( $\left.95 \% \mathrm{Cl} 1.28,1.37\right)$ 
increased dietary intakes of vitamin $\mathrm{C}$, potassium, and calcium by a meaningful amount, but fiber was only modestly increased (i.e., less than a $10 \%$ relative change from observed diets). These nutrient gains were accompanied by only a modest increase in energy intakes $(+4.5 \%$ for the entire population and $+6.6 \%$ for those with a fruit shortfall). Consumption of vitamin $\mathrm{C}$ is generally adequate, so increasing vitamin $\mathrm{C}$ intake is unlikely to have a benefit to public health [37]. However, increasing potassium, calcium and dietary fiber in the American diet is a priority outlined in the 2010 Dietary Guidelines for Americans [1, 2, 38].

Reaching recommendations using a combination of fruit and juice could be accomplished a much less costly manner than whole fruit alone, though it is important to note that both require an increase in spending. One economically viable option to meet fruit goals is to combine some $100 \%$ fruit juice with whole fruit. Public health interventions to improve the quality of children's diets need to take nutritional, behavioral and economic factors into account.

In terms of diet costs, both potassium and dietary fiber were previously identified as nutrients associated with increased diet costs [26]. This relationship is driven by the higher energy-adjusted cost of some key sources of dietary fiber and potassium, including vegetables and fruit. In the current study, a combination of fruit juice and whole fruit increased potassium intakes by $14-21 \%$ among children/adolescents consuming too little fruit, while the cost of the diet only increased by $7-8 \%$. In a previous study, replacement of fruit juice with different types of whole fruit on a serving-per-serving basis did not result in an increase in diet costs for the entire child/adolescent population, though this study did not evaluate the economic impact of meeting fruit guidelines and instead manipulated existing dietary habits [39].

Beyond economic constraints, there are additional challenges in increasing whole fruit consumption among children. One factor that might drive a preference for fruit juice over whole fruit includes the ease of storage, preparation and portioning, which may be particularly important in institutional settings [41]. Spoilage and wastage due to over-ripening of fresh fruit is also a challenge. According to USDA estimates, $25 \%$ of fresh fruit at the consumer level is lost due to over-ripening or spoilage, compared to $11 \%$ for processed fruits (which includes fruit juice along with canned and frozen fruit) [42]. Furthermore, fruit juices may be more convenient for parents and caregivers who have time constraints and may look for easy and quick options [40, 41]. Beyond individual-level barriers, there is some evidence that individuals residing in more deprived neighborhoods may have limited access to fresh fruits at local stores [43], which may influence fresh/whole fruit consumption [44].
In addition, while access to whole/fresh fruit in stores may vary by neighborhood characteristic and type of store, fruit juice is generally available [45].

This study had a number of limitations. First, the consequences of adding whole fruit and fruit juice to diets of children to remove any shortfall in fruit consumption fails to measure the actual dietary behavior of children/ adolescents. As such, our findings represent an estimate of the potential dietary and economic impact of adding fruit juice/whole fruit to the diets of children/adolescents. As a related issue, this model often included small amounts of juice (e.g., 1-2 fluid ounces), which would be difficult to consume in a real-world setting, where most children likely consume juice from larger cups or packages. A second limitation is that our models did not explore other potential substitution scenarios that may improve diet quality for children/adolescents. For example, replacing snacks foods or desserts with whole fruit would further reduce total energy intake, increase nutrient density and fruit consumption, while reducing consumption of added sugars, sodium or solid fats. Determining the foods to replace with fruit is a subjective exercise, and may fail to capture probable dietary behaviors. In addition, this analysis did not evaluate the nutritional or economic consequences of altering other components of the diet, such as increasing vegetable or whole grain consumption. Third, the monetary cost of adding whole fruit and fruit juice to the diets of children is based on a single, nationally representative database of prices that does not account for seasonal or regional variations in food prices, or difference in prices between stores and restaurants.

\section{Conclusions}

Increasing fruit consumption among American children and adolescents is an important component of improving diet quality and nutrient adequacy in this population. While both approaches used here to fill the fruit shortfall resulted in beneficial changes to vitamin $C$, dietary fiber, potassium and calcium consumption, the whole fruit alone model was clearly superior for dietary fiber, but the combined model was superior for the other nutrients, and was able to fill the shortfall in fruit consumption at a significantly lower-cost than through whole fruit alone. Whether whole fruit or a combination of whole fruit and modest amounts of fruit juice are used to address the fruit shortfall, there will be beneficial effects on diet quality and nutrient adequacy. Within cost constraints, a combination of whole fruit and $100 \%$ fruit juice, capped at AAP recommended values, may be a viable option to improve the nutrient adequacy, particularly in terms of vitamin $\mathrm{C}$, potassium and calcium, of diets consumed by American children and adolescents. It is important to note that the combination of 
fruit juice and whole fruit provided much less dietary fiber than the use of whole fruit alone. In addition, interventions or policies that can increase consumption of whole fruit in as cost-neutral a manner as possible should also be considered. Such strategies may include subsidies or increased marketing of whole fruit, as well as development of novel and convenient packaged or pre-sliced fruits, which may be more readily incorporated in school or childcare settings.

\section{Abbreviations}

AAP, American Academy of Pediatrics; CNPP, Center for Nutrition Policy and Promotion; MPED, MyPyramid Equivalents Database; NHANES, National Health and Nutrition Examination Survey; QFAHPD, Quarterly Food At-Home Price Database; USDA, United States Department of Agriculture; WIC, Women, Infants and Children program

\section{Acknowledgements}

Funding for this project was provided from a grant from the Juice Products Association to the University of Washington. The sponsor approved a study proposal but had no role in the design, analysis, interpretation or decision to publish the manuscript.

\section{Authors' contributions}

$C R$ and $A D$ designed this research. CR performed the statistical analysis. CR and $A D$ wrote the manuscript. CR had full access to all of the data in the study and takes responsibility for the integrity of the data and the accuracy of the data analysis. All authors read and approved the final manuscript.

\section{Competing interests}

AD has received grants, honoraria, and consulting fees from numerous food and beverage companies and other commercial and nonprofit entities with interests in nutritive and non-nutritive sweeteners. The University of Washington has received grants, donations, and contracts from both the public and the private sector. CR has no competing interests to declare.

\section{Author details}

'Department of Epidemiology and Center for Public Health Nutrition, University of Washington, Box 353410, Seattle, WA 98195, USA. ${ }^{2}$ Institute for Cardiometabolism and Nutrition (ICAN), Université Pierre et Marie Curie Paris VI, Groupe Hospitalier Pitié-Salpêtrière, 91 boulevard de I'Hôpital, 75013 Paris, France.

Received: 7 August 2014 Accepted: 1 July 2016

Published online: 07 July 2016

\section{References}

1. U.S. Department of Agriculture, U.S. Department of Health and Human Services. Report of the Dietary Guidelines Advisory Committee on the Dietary Guidelines for Americans 2010. Available at: http://origin.www.cnpp. usda.gov/DGAs2010-DGACReport.htm [Accessed April 2014].

2. U.S. Department of Agriculture, U.S. Department of Health and Human Services. Dietary Guidelines for Americans 2010. Available at: http://www. health.gov/dietaryguidelines/dga2010/dietaryguidelines2010.pdf [Accessed April 2014].

3. United States Department of Agriculture. ChooseMyPlate.gov. Available at: http://www.choosemyplate.gov/[Accessed March 2014].

4. Lorson BA, Melgar-Quinonez HR, Taylor CA. Correlates of fruit and vegetable intakes in US children. J Am Diet Assoc. 2009;109(3):474-8.

5. Wolfenden L, Wyse RJ, Britton BI, Campbell KJ, Hodder RK, Stacey FG, McElduff $\mathrm{P}$, James EL. Interventions for increasing fruit and vegetable consumption in children aged 5 years and under. Cochrane Database Syst Rev. 2012;11:CD008552

6. Ohri-Vachaspati P, Turner L, Chaloupka FJ. Fresh Fruit and Vegetable Program participation in elementary schools in the United States and availability of fruits and vegetables in school lunch meals. J Acad Nutr Diet. 2012;112(6):921-6.
7. Baranowski T, Diep C, Baranowski J. Influences on children's dietary behavior, and innovative attempts to change it. Ann Nutr Metab. 2013;62 Suppl 3:38-46

8. Aggett PJ, Haschke F, Heine W, Hernell O, Koletzko B, Lafeber H, Ormission A, Rey J, Tormo R. Committee report: childhood diet and prevention of coronary heart disease. ESPGAN Committee on Nutrition. European Society of Pediatric Gastroenterology and Nutrition. J Pediatr Gastroenterol Nutr. 1994;19(3):261-9.

9. Gan Y, Tong X, Li L, Cao S, Yin X, Gao C, Herath C, Li W, Jin Z, Chen Y, Lu Z. Consumption of fruit and vegetable and risk of coronary heart disease: $A$ meta-analysis of prospective cohort studies. Int J Cardiol. 2015;183C:129-37.

10. Wojcicki JM, Heyman MB. Reducing childhood obesity by eliminating $100 \%$ fruit juice. Am J Public Health. 2012;102(9):1630-3.

11. Faith MS, Dennison BA, Edmunds LS, Stratton HH. Fruit juice intake predicts increased adiposity gain in children from low-income families: weight status-by-environment interaction. Pediatrics. 2006;118(5):2066-75.

12. Muraki I, Imamura F, Manson JE, Hu FB, Willett WC, van Dam RM, Sun Q. Fruit consumption and risk of type 2 diabetes: results from three prospective longitudinal cohort studies. BMJ. 2013;347:f5001.

13. Committee on Nutritio. The use and misuse of fruit juice in pediatrics. Pediatrics. 2001;107(5):1210-3.

14. Andreyeva T, Luedicke J, Tripp AS, Henderson KE. Effects of reduced juice allowances in food packages for the women, infants, and children program. Pediatrics. 2013;131(5):919-27.

15. Bihan H, Castetbon K, Mejean C, Peneau S, Pelabon L, Jellouli F, Le Clesiau $\mathrm{H}$, Hercberg S. Sociodemographic factors and attitudes toward food affordability and health are associated with fruit and vegetable consumption in a low-income French population. J Nutr. 2010;140(4):823-30.

16. Dennison BA, Rockwell HL, Baker SL. Excess fruit juice consumption by preschool-aged children is associated with short stature and obesity. Pediatrics. 1997;99(1):15-22.

17. Drewnowski A, Darmon N, Briend A. Replacing fats and sweets with vegetables and fruits-a question of cost. Am J Public Health. 2004;94(9):1555-9.

18. Rehm CD, Monsivais $P$, Drewnowski $A$. The quality and monetary value of diets consumed by adults in the United States. Am J Clin Nutr. 2011;94:1333-9.

19. Rehm CD, Monsivais P, Drewnowski A. Relation between diet cost and Healthy Eating Index 2010 scores among adults in the United States 2007-2010. Prev Med. 2015:73C:70-5.

20. Rasmussen M, Krolner R, Klepp Kl, Lytle L, Brug J, Bere E, Due P. Determinants of fruit and vegetable consumption among children and adolescents: a review of the literature. Part I: Quantitative studies. Int J Behav Nutr Phys Act. 2006;3:22

21. Drewnowski A, Rehm CD. Socioeconomic gradient in consumption of whole fruit and $100 \%$ fruit juice among US children and adults. Nutr J. 2015;14:3.

22. Anderson AS, Cox DN, McKellar S, Reynolds J, Lean ME, Mela DJ. Take Five, a nutrition education intervention to increase fruit and vegetable intakes: impact on attitudes towards dietary change. Br J Nutr. 1998;80(2):133-40.

23. Rolls BJ, Ello-Martin JA, Tohill BC. What can intervention studies tell us about the relationship between fruit and vegetable consumption and weight management? Nutr Rev. 2004;62(1):1-17.

24. Ha EJ, Caine-Bish N. Effect of nutrition intervention using a general nutrition course for promoting fruit and vegetable consumption among college students. J Nutr Educ Behav. 2009;41(2):103-9.

25. Ammerman AS, Lindquist $\mathrm{CH}$, Lohr KN, Hersey J. The efficacy of behavioral interventions to modify dietary fat and fruit and vegetable intake: a review of the evidence. Prev Med. 2002;35(1):25-41.

26. Monsivais P, Aggarwal A, Drewnowski A. Following federal guidelines to increase nutrient consumption may lead to higher food costs for consumers. Health Aff (Millwood). 2011;30(8):1471-7.

27. Thompson FE, McNeel TS, Dowling EC, Midthune D, Morrissette M, Zeruto CA. Interrelationships of added sugars intake, socioeconomic status, and race/ethnicity in adults in the United States: National Health Interview Survey, 2005. J Am Diet Assoc. 2009:109(8):1376-83.

28. Dodd KW, Guenther PM, Freedman LS, Subar AF, Kipnis V, Midthune D, Tooze JA, Krebs-Smith SM. Statistical methods for estimating usual intake of nutrients and foods: a review of the theory. J Am Diet Assoc. 2006;106(10):1640-50.

29. Bowman S, Friday J, Moshfegh AJ. MyPyramid Equivalents Database, 2.0 for USDA Survey Foods, 2003-2004: documentation and user guide Available at: http://www.ars.usda.gov/SP2UserFiles/Place/12355000/pdf/mped/ mped2_doc.pdf [Accessed April 2014]. 
30. Monsivais P, Drewnowski A. The rising cost of low-energy-density foods. J Am Diet Assoc. 2007;107(12):2071-6.

31. Christian T, Rashad I. Trends in U.S. food prices, 1950-2007. Econ Hum Biol. 2009:7(1):113-20.

32. Centers for Disease Control and Prevention (CDC). Vital signs: food categories contributing the most to sodium consumption - United States, 2007-2008. MMWR Morb Mortal Wkly Rep. 2012;61(5):92-8.

33. United States Department of Agriculture, Economic Research Service. Quarterly Food-at-Home Price Database. Available at: http://www.ers.usda. gov/data-products/quarterly-food-at-home-price-database.aspx\#. UoKkq5Q0iOy [Accessed July 2013].

34. Gidding SS, Dennison BA, Birch LL, Daniels SR, Gillman MW, Lichtenstein AH, Rattay KT, Steinberger J, Stettler N, Van Horn L. Dietary recommendations for children and adolescents: a guide for practitioners. Pediatrics. 2006; 117(2):544-59.

35. Monsivais $\mathrm{P}$, Johnson DB. Improving nutrition in home child care: are food costs a barrier? Public Health Nutr. 2012;15(2):370-6.

36. Briley ME, Roberts-Gray C, Simpson D. Identification of factors that influence the menu at child care centers: a grounded theory approach. J Am Diet Assoc. 1994;94(3):276-81.

37. Schleicher RL, Carroll MD, Ford ES, Lacher DA. Serum vitamin C and the prevalence of vitamin C deficiency in the United States: 2003-2004 National Health and Nutrition Examination Survey (NHANES). Am J Clin Nutr. 2009; 90(5):1252-63.

38. Hoy M, Goldman J. Potassium intake of the US population: what we eat in America, NHANES 2009-2010. Available at: http://ars.usda.gov/SP2UserFiles/Place/ 12355000/pdf/DBrief/10_potassium_intake_0910.pdf [Accessed April 2014]

39. Monsivais P, Rehm CD. Potential nutritional and economic effects of replacing juice with fruit in the diets of children in the United States. Arch Pediatr Adolesc Med. 2012;166(5):459-64.

40. Buzby JC, Wells HF, Hyman J. The estimated amount, value, and calories of postharvest food losses at the retail and consumer levels in the United States. Available at: http://www.ers.usda.gov/publications/eib-economicinformation-bulletin/eib121.aspx\#.UoW6HFca18H [Accessed April 2014].

41. Devine CM, Jastran M, Jabs J, Wethington E, Farell TJ, Bisogni CA. "A lot of sacrifices:" work-family spillover and the food choice coping strategies of low-wage employed parents. Soc Sci Med. 2006;63(10):2591-603.

42. Jabs J, Devine CM, Bisogni CA, Farrell TJ, Jastran M, Wethington E. Trying to find the quickest way: employed mothers' constructions of time for food. J Nutr Educ Behav. 2007;39(1):18-25.

43. Bodor JN, Rice JC, Farley TA, Swalm CM, Rose D. Disparities in food access: does aggregate availability of key foods from other stores offset the relative lack of supermarkets in African-American neighborhoods? Prev Med. 2010; 51(1):63-7.

44. Zenk SN, Lachance LL, Schulz AJ, Mentz G, Kannan S, Ridella W. Neighborhood retail food environment and fruit and vegetable intake in a multiethnic urban population. Am J Health Promot. 2009;23(4):255-64.

45. Andreyeva T, Blumenthal DM, Schwartz MB, Long MW, Brownell KD. Availability and prices of foods across stores and neighborhoods: the case of New Haven, Connecticut. Health Aff (Millwood). 2008:27(5):1381-8.

\section{Submit your next manuscript to BioMed Central and we will help you at every step:}

- We accept pre-submission inquiries

- Our selector tool helps you to find the most relevant journal

- We provide round the clock customer support

- Convenient online submission

- Thorough peer review

- Inclusion in PubMed and all major indexing services

- Maximum visibility for your research

Submit your manuscript at www.biomedcentral.com/submit 